\title{
Analysis of Reducing Characteristics of Direct Reduced Iron using Blast Furnace Dust
}

\author{
Young Min Yun, Yong Sik Chư, Sung Kwan Seo, and Jae Hyun Jeong \\ Energy and Environmental Division, Korea Institute of Ceramic Engineering and Technology, Jinju 52851, Korea
}

(Received May 4, 2016; Revised July 6, 2016; Accepted July 18, 2016)

\begin{abstract}
Industrial by-products generated by integrated iron and steel manufacture cause environmental pollution. The by-products contain not only iron element but also harmful substances. Therefore, in view of to waste recycling and environmental preservation, production of sponge iron using the by-product is considered an effective recycling method. In this study, reduction efficiency of pellets from blast furnace dust was measured. Metallization was found to be increased, as $\mathrm{C} / \mathrm{Fe}_{\text {total }}$ ratio and reaction time were increased. The pellets were formed into a globular shape, and calcined for 60 minutes at $1100^{\circ} \mathrm{C}$ in an electric furnace. Phase changes were analyzed using an X-ray diffractometer. Microstructures of the pellets were observed by a scanning electron microscope.
\end{abstract}

Key words : Blast furnace dust, Metallization, Waste recycling, Sponge iron

\section{Introduction}

$\mathbf{R}$ ecently, the demand stagnation of China accounting for about $50 \%$ of the global steel demand is affecting slowdown in the steel demand. As a result, the prices of iron ore and iron scrap have been dropped since 2013 due to supply surplus phenomenon of raw materials for steel. Therefore, use expansion of low-cost raw materials and production technologies for high-quality iron sources are being required for reinforcement of steel companies' competitiveness resulting from lowered price competitiveness of direct reduced iron. As the dust, sludge, etc. currently produced in steelmaking processes contain iron oxides, there are advantages in their use as a substitute raw material for iron ore to produce direct reduced iron. ${ }^{1,2)}$ Among the advantages, blast furnace dust as a representative byproduct of steelmaking process has a very high content of iron oxide so as to facilitate manufacturing of direct reduced iron.

Global production of direct reduced iron in 2014 was 75 million tons, or a scale grown by about 95 times as compared with 1970 (790,000 tons), of which 33 million tons were produced in Asia/Oceania, 19 million tons in Mideast/ North Africa, and 13 million tons in Latin America including Mexico, etc. The domestic market of reduced iron is dependent on import volumes, and about 500,000 600,000 tons were annually imported from India, Venezuela, etc. ${ }^{3)}$ However, as the drop in prices of iron ores is extended over a long period, domestic steel manufacturers are almost not

${ }^{\dagger}$ Corresponding author: Yong Sik Chu

E-mail : yschu@kicet.re.kr

Tel : +82-55-792-2463 Fax : +82-55-792-2458 importing any direct reduced iron.

In general, direct reduced iron is reduced and manufactured from iron ores in solid state, where coal or carbon monoxide is used as a reducing agent (see Fig.1). Stepwise reduction reaction of iron oxide proceeds in the order of $\mathrm{Fe}_{2} \mathrm{O}_{3}$ (hematite, $\left.\mathrm{HCP}\right) \rightarrow \mathrm{Fe}_{3} \mathrm{O}_{4}$ (magnetite, cubic) $\rightarrow \mathrm{FeO}$ (wustite, cubic) $\rightarrow \mathrm{Fe}$ (metallic iron, BCC or FCC), and may be represented as shown by the following expressions 1,2 and $3 .^{4,5)}$

$$
\begin{aligned}
& \mathrm{Fe}_{2} \mathrm{O}_{3}+\mathrm{C} \rightarrow \mathrm{Fe}_{3} \mathrm{O}_{4}+\mathrm{CO} \\
& \mathrm{Fe}_{3} \mathrm{O}_{4}+\mathrm{C} \rightarrow \mathrm{FeO}+\mathrm{CO} \\
& \mathrm{FeO}+\mathrm{C} \rightarrow \mathrm{Fe}+\mathrm{CO}
\end{aligned}
$$

In the present study, manufacturing experiments of direct reduced iron were conducted by using blast furnace dust produced as a byproduct from steelmaking process. In the present experiment, green compacts of blast furnace dust and anthracite were mixed together and sintered for reduction characteristics analysis of the direct reduced iron, where reduction efficiency and phase transition characteris-
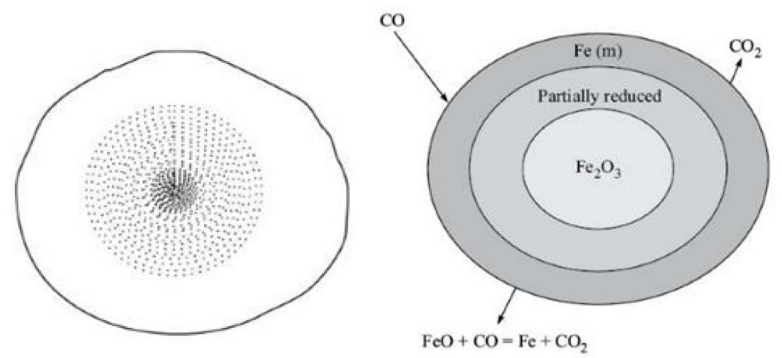

Fig. 1. Cross-section of a partially reduced porous iron ore pellet. 
Table 1. Chemical Analysis of Blast Furnace Dust

(unit:wt\%)

\begin{tabular}{cccccccc}
\hline No. & Total Fe & Metal Fe & $\mathrm{Al}_{2} \mathrm{O}_{3}$ & $\mathrm{CaO}$ & $\mathrm{SiO}_{2}$ & $\mathrm{C}$ & $\mathrm{S}$ \\
\hline Blast furnace dust & 61.5 & 1.3 & 0.7 & 1.4 & 2.6 & 5.8 & 0.3 \\
\hline
\end{tabular}

Table 2. Chemical Analysis of Coal

Anthracite

\begin{tabular}{ccc}
$\mathrm{Fe}_{2} \mathrm{O}_{3}$ & $\mathrm{SiO}_{2}$ & $\mathrm{Al}_{2} \mathrm{O}_{3}$ \\
\hline 1.8 & 0.6 & 0.3
\end{tabular}

$\begin{array}{cccc}\mathrm{CaO} & \mathrm{MgO} & \mathrm{S} & \text { LOI } \\ 1.1 & 0.3 & 0.4 & 95.5\end{array}$

tics were analyzed and evaluated.

\section{Experimental Procedure}

\subsection{Starting raw material}

In the present study, blast furnace dust as a steelmaking byproduct was used for manufacturing of direct reduced iron. For coal, domestically produced anthracite was used, with the chemical compositions of blast furnace dust and anthracite as a reducing agent being shown in Table 1 and 2 . Table 3 shows the proximate analysis of Anthracite coal, fixed carbon found to be $84.6 \%$, moisture $1.6 \%$, ash $5.8 \%$, volatile matter $7.9 \%$. The blast furnace dust is an iron-containing byproduct with total Fe content of $61.5 \mathrm{wt} \%$, and a mean particle diameter of $35 \mu \mathrm{m}$. Ignition loss of the domestically produced anthracite was $95.5 \mathrm{wt} \%$, and the fixed carbon content $84.6 \mathrm{wt} \%$. In addition, an XRD pattern for blast furnace dust as the raw material is shown in Fig. 2, most of which is present in the form of $\mathrm{Fe}_{2} \mathrm{O}_{3}$.

\subsection{Preparation and analysis of specimens}

Blast furnace dust is in a fine powder form of $35 \mu \mathrm{m}$ in mean particle diameter, and feeding becomes difficult due to scattering by the in-furnace heat flow and the produced gas when fed in a powder state. Therefore, it should be fed by controlling its size and shape so as to have a given specific weight. Thus, in the present study, manufacturing of

Table 3. Analysis of Coal

\begin{tabular}{ccccc}
\hline \multirow{2}{*}{ Anthracite } & $\mathrm{FC}, \mathrm{ad} / \%$ & $\mathrm{M}, \mathrm{ad} / \%$ & $\mathrm{~A}, \mathrm{ad} / \%$ & $\mathrm{~V}$, daf $/ \%$ \\
\cline { 2 - 5 } & 84.6 & 1.6 & 5.8 & 7.9 \\
\hline
\end{tabular}

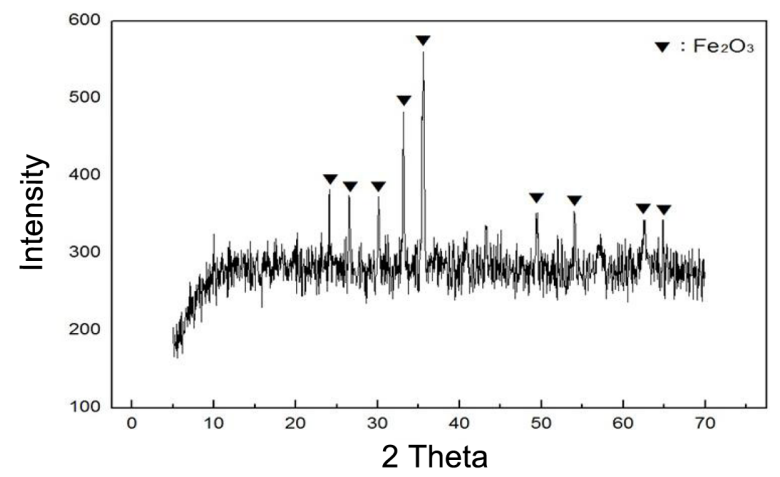

Fig. 2. XRD pattern of blast furnace dust. globular green compacts was attempted by mixing blast furnace dust with water. Here, the ratio for fine dust and water was fixed at $30 \%$, and the weight of green compact at $3 \mathrm{~g}$. Diameters of thus-produced green compact pellets were around $10 \mathrm{~mm}$. They were dried under $120^{\circ} \mathrm{C}$ condition until a constant weight was obtained. The green compacts subjected to constant-weight drying were mixed with anthracite as the reducing agent and then loaded into an alumina crucible, where the mixing ratios between green compact and anthracite were controlled to be $1: 0.5,1,1.5$, and 2 . Subsequently, the alumina crucible was positioned in an electric furnace and held at $1100^{\circ} \mathrm{C}$ for $0 \mathrm{~min}, 20 \mathrm{~min}, 40$ $\mathrm{min}$, and $60 \mathrm{~min}$. Reduced iron out of the furnace was then subjected to the analysis for crystalline phases using an Xray diffractometer (Dmax2500, Rigaku, Japan). Shapes of the reduced iron were observed using a stereoscopic microscope, and microstructures were examined using a scanning electron microscope (SM-300, Topcon). In addition, Total Fe and metallic Fe were found by wet and instrumental analyses, and reduction efficiencies were calculated according to the expression (4).

$$
\frac{\text { Metal Fe }(w t \%)}{\text { Total Fe }(w t \%)} \times 100
$$

\section{Results and Discussion}

\subsection{Reduced iron shape}

Reduced iron of blast furnace dust in globular shape produced in different mixing ratios and reduced for different times was observed using a stereoscopic microscope, as shown in Fig. 3. As indicated in Fig. 3, multitude of radial cracks were produced across the cross section for the mixing ratio of the green compact and anthracite $1: 0.5$ and reduction time of $60 \mathrm{~min}$. Radial cracks increased with smaller proportion of anthracite and longer reduction time. In general, direct reduced iron is manufactured by reaction between iron oxides inside iron ore and solid carbon or reducing gas (carbon monoxide, etc.). ${ }^{6)}$ Oxygen content is increased as the iron oxide content present in iron-containing products is increased, and this oxygen escapes as carbon dioxide in the reduction process. ${ }^{78}$ At this time, oxygen sites within iron oxide remain as a vacant space, which was considered to act as a source for crack generation during calcination shrinkage. ${ }^{9)}$

As shown in Fig. 1, reduction of iron oxide generally occurs from the surface, and then gradually extends inward. 

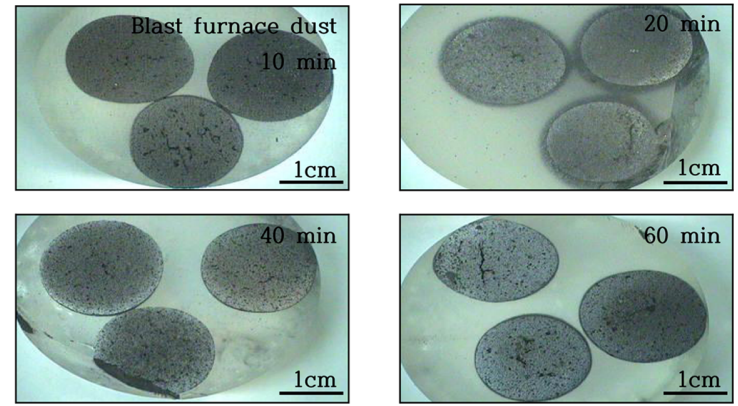

(A) Blast furnace dust DRI (1:0.5)
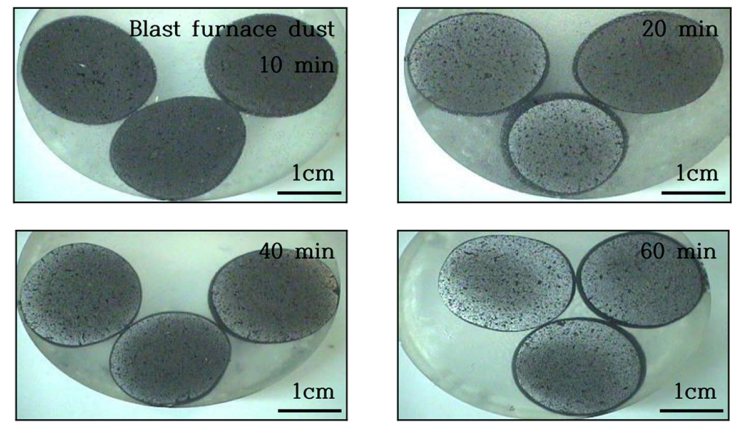

(C) Blast furnace dust DRI (1:1.5)
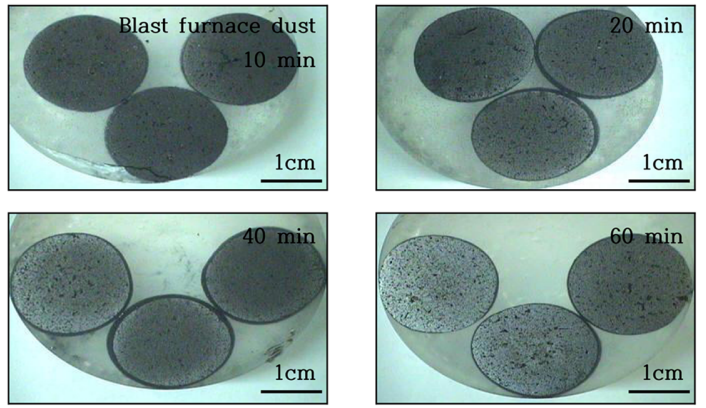

(B) Blast furnace dust DRI $(1: 1)$
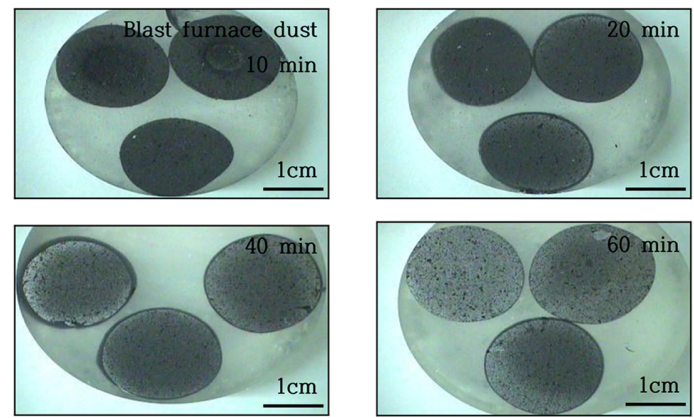

(D) Blast furnace dust DRI $(1: 2)$

Fig. 3. Morphology of DRI of different mixing ratios and reduction times.

Here, the center part of reduced sintered body is known to consist of hematite crystals, sequentially followed by formation of magnetite, wustite and porous metal iron on the surface layer. ${ }^{8)}$ The extension of the reduction front the surface into the center of the pellets with increasing reduction time can be seen in the images of Fig. 3. Gray rims indicating the inward moving of reduction boundary can be distinguished for the reduction time $20 \mathrm{~min}$. In general, upon reduction reaction between iron ore and anthracite, the reducing gas (CO) is diffused into the sphere interior, and the produced gas $\left(\mathrm{CO}_{2}\right)$ is moved to outside of the sintered body. ${ }^{10,11)}$ Consequently, vacant spaces of oxygen atoms resulting from oxygen breakaway are increased with increase in sintering time, which facilitates movement of reducing gas, etc. In the present experiments, diffusion of grey part up to sphere interior was also affirmed in the sintered body with $60 \mathrm{~min}$ of reduction under the mixing condition of $1: 2$ between blast furnace dust and anthracite. Based on this observation, reduction reaction is presumed to have occurred throughout the sphere cross section.

\subsection{Microstructure of reduced iron}

To observe microstructures in different mixing ratios between green compact of blast furnace dust and anthracite, a scanning electron microscope was employed, the results of which are shown in Fig. 4. In all prepared specimens, the particle sizes of sintered body with $10 \mathrm{~min}$ of reduction were not constant, and presence of a small amount of pores could also be observed. At the reduction time of $60 \mathrm{~min}$, particle size and distribution were homoge- nized, and ellipsoidal particles appear to have surface dissolved. With increasing reduction time from 10 to $60 \mathrm{~min}$, particle or grain growth, decrease in fine pores and densification have occurred. This is also the result similar to that of iron oxide reduction published by Wagner et al. ${ }^{12)}$ Wagner et al. have made an observation of microstructures as a function of reduction time, where ellipsoidal and linear particles and fine pores were also present in the reduced iron.

The reduction condition of $10 \mathrm{~min}$ for all green compacts was considered to involve a reduction stage where phase transformation occurred from hematite $\left(\mathrm{Fe}_{2} \mathrm{O}_{3}\right)$ to magnetite $\left(\mathrm{Fe}_{3} \mathrm{O}_{4}\right)$, which could be inferred from the volume increase (20\%) of a sintered body. ${ }^{13)}$ Most particles had a size of around $10 \mu \mathrm{m}$, and nonuniform particles were also observed. At the reduction times of $20 \mathrm{~min}$ and $40 \mathrm{~min}$, wustite $(\mathrm{FeO})$ particles in ellipsoidal shape were presumably produced and the neighboring particles appeared to have agglomerated together, which cause the deformation of the pellets from inside. For the reduction time of $60 \mathrm{~min}$, the crystal structure was transformed from wustite $(\mathrm{FeO})$ to iron $(\mathrm{Fe})$, where Fe crystals were grown by being connected to thesurrounding particles on the particle surface. ${ }^{14)}$ Therefore, Fe particles were considerably continuous with presence of pores.

Particle size under the reduction time condition of $60 \mathrm{~min}$ was $10 \sim 20 \mu \mathrm{m}$, with pore size also being on the level less than $20 \mu \mathrm{m}$, which is the form similar to the reported microstructures of the existing reduced iron. ${ }^{15)}$ The reduced particles were grown into ellipsoidal and linear forms with increase in $\mathrm{CO}$ and reduction time, and wustite $(\mathrm{FeO})$ was 

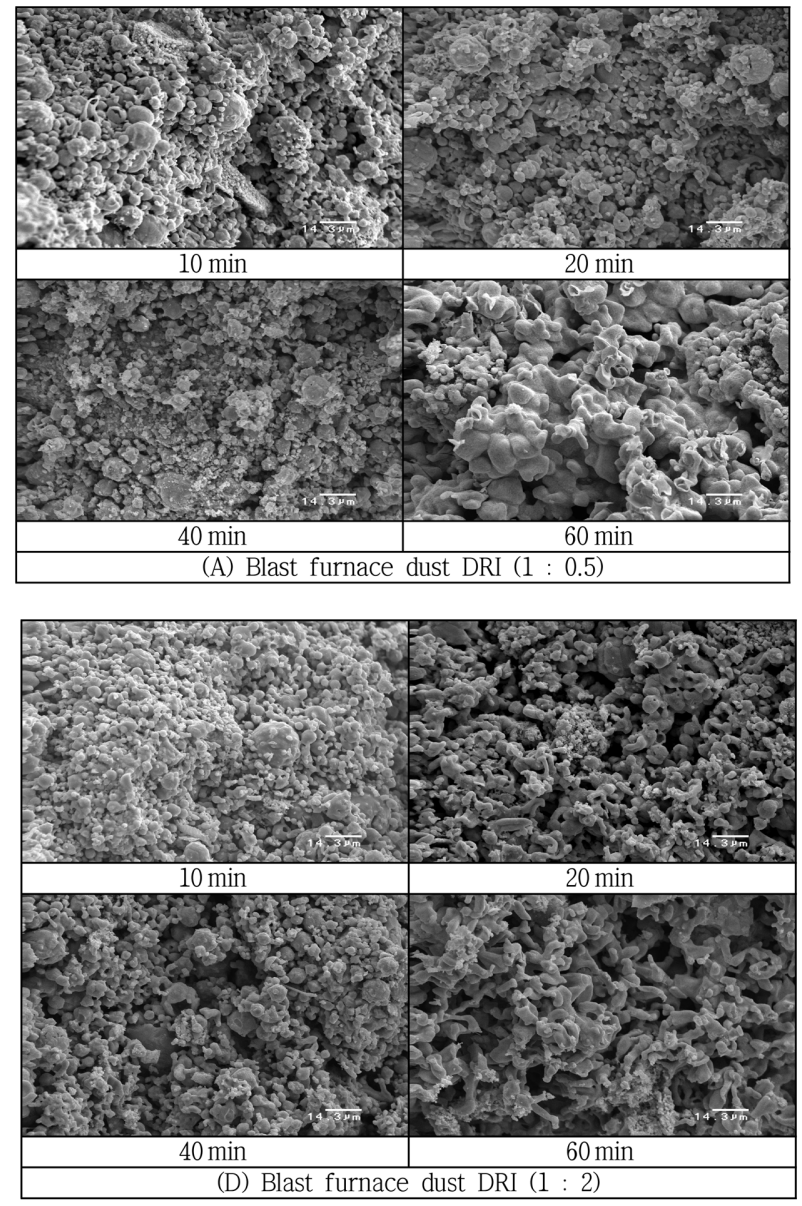

Fig. 4 Microstructure of blast furnace dust DRI.

observed as a part with the particle surface being small and bright. Particle growth from wustite $(\mathrm{FeO})$ to iron $(\mathrm{Fe})$ requires a reduction time, and the initial oxygen content is known to have a large effect. ${ }^{16)}$ Therefore, oxygen breakaway is being reported to be increased as the initial iron oxide content is increased, and to have a favorable effect on iron particle growth. ${ }^{17)}$

\subsection{Crystallinity analysis of reduced iron}

For crystallinity analysis of reduced iron from blast furnace dust, an X-ray diffractometer was employed, and respective XRD patterns for different mixing ratios between green compact and anthracite are shown in Fig. 5. Major crystalline phase of blast furnace dust prepared in pellets before calcination was $\mathrm{Fe}_{2} \mathrm{O}_{3}$, and $\mathrm{Fe}$ peak intensity was increased in (a) and (b) under the reduction time condition of $20 \mathrm{~min}$, while $\mathrm{FeO}$ peak intensity was increased in (c) and (d). In addition, iron oxide could also be seen to remain in the sintered body. Under the reduction condition of $40 \mathrm{~min}$, Fe peak intensity was increased in all of (a), (b), (c), and (d). Particularly, Fe crystals were primarily observed under the condition of 60 min so that most of iron oxides could be confirmed to have been reduced. Changes in crystal phases occurred in the order of $\mathrm{Fe}_{2} \mathrm{O}_{3} \rightarrow \mathrm{Fe}_{3} \mathrm{O}_{4} \rightarrow \mathrm{FeO} \rightarrow \mathrm{Fe}$ with
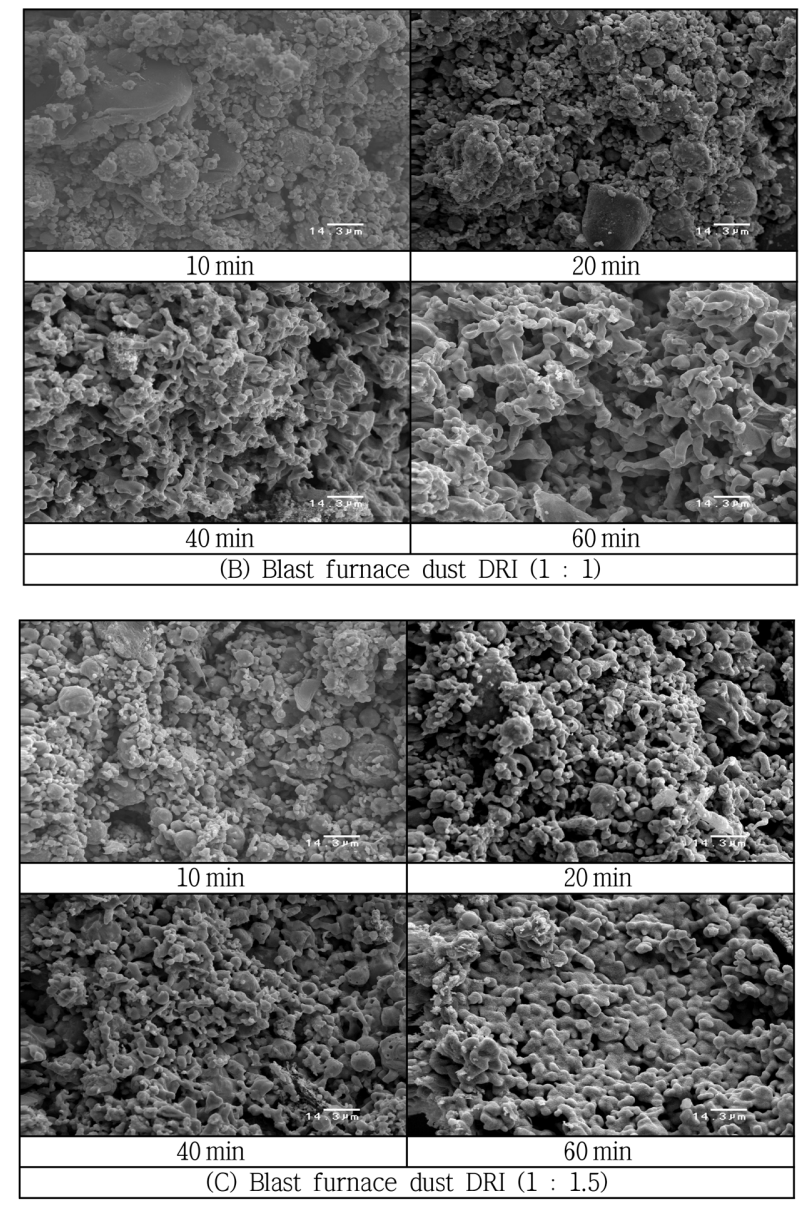

increase in the reduction time and the mixed amount of anthracite. The increase in reducing agent anthracite was considered to have an effect on Fe crystallinity as indicated by the increase in Fe peak intensity.

\subsection{Reduction efficiency of reduced iron}

Total Fe and metallic Fe of all sintered bodies in different mixing ratios between blast furnace dust pellets and anthracite and reduction time changed were subjected to wet and instrumental analyses (KS E ISO 2597-1, 5416), and the corresponding calculated reduction efficiencies are shown in Table 4. Initial total Fe content of blast furnace dust was $61.5 \mathrm{wt} \%$, and the reduction efficiencies together with total Fe and metallic Fe contents showed a gradual increase with increase in reduction time. For the reduction time $60 \mathrm{~min}$, the respective reduction efficiencies of the mixing ratios $0.5,1,1.5$ and 2 were $69.4 \mathrm{wt} \%, 74.2 \mathrm{wt} \%, 88.9 \mathrm{wt} \%$, and $96.8 \mathrm{wt} \%$. The increase in the reduction time and the mixed amount of anthracite at a given reduction temperature was considered to have an enormous effect on improvement of reduction efficiency.

Figure 6 shows a graph of reduction efficiencies as a function of mixing ratios between blast furnace dust and anthracite as well as reduction time, displaying the increase in 


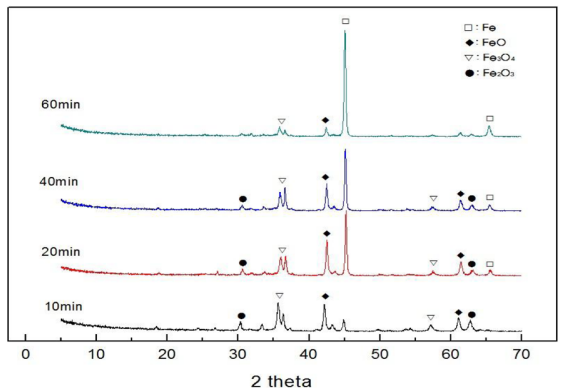

(a) Blast furnace dust DRI (1: 0.5)

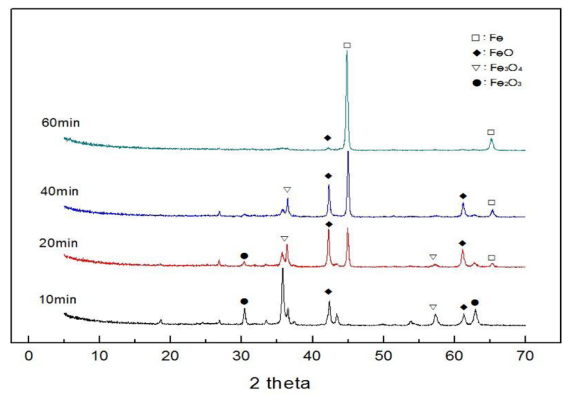

(c) Blast furnace dust DRI $(1: 1.5)$

Fig. 5. XRD patterns of DRI.

Table 4. Chemical Analysis of Blast Furnace Dust

\begin{tabular}{ccccc}
\hline \multirow{2}{*}{$\begin{array}{c}\text { Reduced } \\
\text { time(min) }\end{array}$} & $\begin{array}{c}\text { Dust/coal } \\
\text { Ratio }\end{array}$ & $\begin{array}{c}\text { Chemical Analysis } \\
\text { (wt\%) }\end{array}$ & $\begin{array}{c}\text { Metallization } \\
\text { degree (\%) }\end{array}$ \\
\cline { 3 - 4 } & 0.5 & Total Fe & Metal Fe & \\
\hline \multirow{2}{*}{10} & 1 & 67.8 & 1.0 & 1.5 \\
& 1.5 & 69.2 & 1.0 & 1.5 \\
& 2 & 71.2 & 1.3 & 1.9 \\
& 0.5 & 74.1 & 14.8 & 7.4 \\
20 & 1 & 74.1 & 20.1 & 20.0 \\
& 1.5 & 77.6 & 22.0 & 27.1 \\
& 2 & 77.9 & 23.2 & 29.4 \\
& 0.5 & 78.2 & 30.6 & 39.1 \\
40 & 1 & 79.5 & 33.7 & 42.4 \\
& 1.5 & 80.2 & 35.4 & 44.1 \\
& 2 & 80.4 & 38.1 & 47.4 \\
& 0.5 & 80.5 & 55.9 & 69.4 \\
& 1 & 80.9 & 60.0 & 74.2 \\
& 1.5 & 81.2 & 72.2 & 88.9 \\
& 2 & 84.1 & 81.4 & 96.8 \\
\hline
\end{tabular}

reduction efficiency with increase in reduction time. Although almost no reduction occurred in all sintered bodies under the reduction time condition of $10 \mathrm{~min}$, the reduction efficiency was drastically increased at the reduction time of $40 \mathrm{~min}$. Subsequently, large differences in reduction efficiencies betweeen mixing ratios were observed for the reduction time of $60 \mathrm{~min}$. Here, the reduction efficiency of

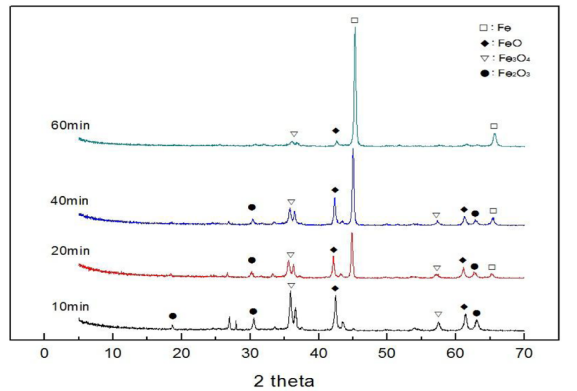

(b) Blast furnace dust DRI $(1: 1)$

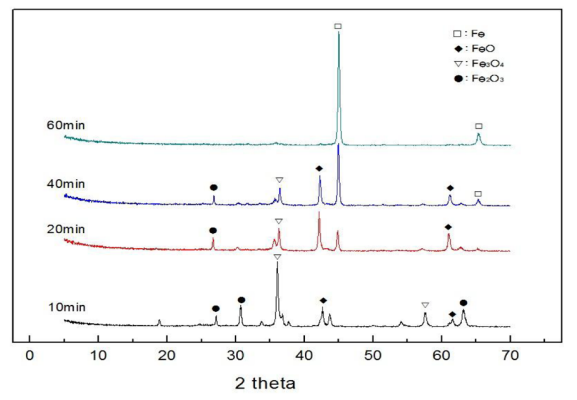

(d) Blast furnace dust DRI $(1: 2)$

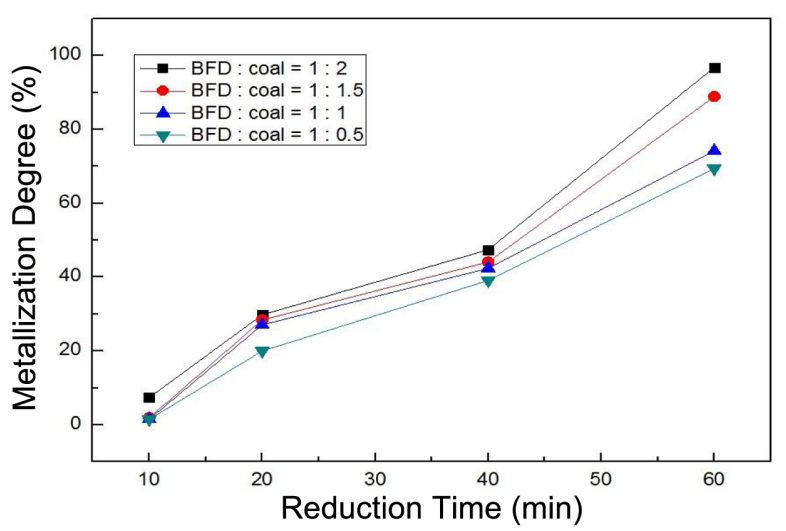

Fig. 6 Metallization degree vs reduction time.

the sample in mixing ratio $1: 2$ between green compact and anthracite was $96.8 \mathrm{wt} \%$, and for the mixing ratio 1:0.5 69.4 wt\% which is decreased by $27.4 \mathrm{wt} \%$. The results showed that the reduction reaction rate was slowed down when the mixed amount of anthracite was insufficient compared with blast furnace dust and the reaction rate was high when the amount was sufficient. In addition, the reduction efficiency of iron oxides published by Liu and Strezov exceeded $90 \mathrm{wt} \%{ }^{18)}$ which was a comparable level to the reduction efficiency of blast furnace dust in the present work.

\section{Conclusions}

In the present study, changes in crystal phases and reduction efficiencies of direct reduced iron were observed for dif- 
ferent mixing ratios mixing ratio between blast furnace dust and anthracite, and the following conclusions have been drawn.

1) The increase in radial cracks with increase in reduction time was observed. In addition, it was also observed that the grey rim developed from the surface extends inward. The phenomena presumably indicate the reduction process inside the pellets. For the reduction time of $60 \mathrm{~min}$, even the center of the cross section of the pellets changed to grey color.

2) With increase in reduction time, particle size and distribution became homogeneous, fine pores increased, and particle densification occurred. The particle size at the reduction time of $60 \mathrm{~min}$ was about $10 \sim 20 \mu \mathrm{m}$, and around 10 $\mu \mathrm{m}$ at the reduction time of $10 \mathrm{~min}$, and particles grew into ellipsoidal and linear shapes with an increase in reduction time.

3) Phase transitions in the blast furnace dust proceeded in the order of $\mathrm{Fe}_{2} \mathrm{O}_{3} \rightarrow \mathrm{Fe}_{3} \mathrm{O}_{4} \rightarrow \mathrm{FeO} \rightarrow$ Fe. Fe and $\mathrm{FeO}$ phases were increased for the reduction time $20 \mathrm{~min}$. At the reduction time of $60 \mathrm{~min}$, iron oxide crystals were greatly reduced, and metallic Fe phase was primarily observed. In addition, Fe crystallinity became higher with increase in reduction time and mixed amount of anthracite.

4) Reduction efficiency exhibited a close correlation with mixing ratios between blast furnace dust and anthracite as well as reduction time. The highest reduction efficiency (96.8 wt\%) was observed when the mixing ratio between blast furnace dust and anthracite was $1: 2$ and the reduction time was $60 \mathrm{~min}$.

5) Blast furnace dust exhibited reduction characteristics similar to those of the existing high-grade iron ores as reduction time and mixed amount of anthracite were increased. Consequently, blast furnace dust was suggested to be used as a substitute material for the iron ores in manufacturing of direct reduced iron.

\section{REFERENCES}

1. Y.-S. Lee and I. Sohn, "Relationship between the Reduction Degree and Strength of DRI Pellets Produced from Iron and Carbon Bearing Wastes Using an RHF Simulator," ISIJ Int., 52 1454-62 (2012).

2. S.-H. Chung and I. Sohn, "DRI from Recycled Iron Bearing Wastes for Lower Carbon in the Blast Furnace," ISIJ Int.,
55 1157-64 (2015).

3. World Direct Reduction Statistics; Midrex Technologies, Inc., Charlotte, North Carolina, USA, pp. 1-15, 2014.

4. L. V. Bogdandy and H. J. Engell, The Reduction of Iron Ores; pp. 289-96, Springer-Verlag, Berlin, 1971.

5. I. Moon and S. Jung, "Reduction of Solid Iron Oxide by Carbon," Steel Res. Int., 79 667-70 (2008).

6. S. Mookherjee, H. S. Ray, and A. Mukherjee, "Isothermal Reduction of Iron Ore Fines Sur-Rounded by Coal or Char Fines," Ironmaking Steelmaking, 13 [5] 229-35 (1986).

7. M. Rahman, R. Haque, and M. M. Haque, "Kinetics of Reduction of Millscale by Coal: Effect of Process Variables," Ironmaking Steelmaking, 22 [2] 166-70 (1995).

8. C. E. Seaton, J. S. Foster, and J. Velasco, "Reduction Kinetics of Hematite and Magnetite Pellets Containing Coal Char," Trans. Iron Steel Inst. Jpn., 23 490-96 (1993).

9. T. Sharma, "Non-Coking Coal Quality and Composite PreReduced Pellets," Int. J. Miner. Process., 39 299-11 (1993).

10. D. Anghelina, G. Brooks, and G. A. Irons, "High Temperature Behaviour of Directly Reduced Iron Fines," Can. Metall. Q., 46 373-78 (2007).

11. N. S. Srinivasan and A. K. Lahiri, "On the Mechanism of Iron Oxide Reduction by Carbon," Metall. Trans. B, 6B 269-74 (1975).

12. D. Wagner, O. Devisme, F. Patisson, and D. Ablitzer, "A Laboratory Study of The Reduction of Iron Oixdes by Hydrogen," Adv. Process. Met. Mater., Sohn Int. Symp., Proc., 2 111-20 (2008).

13. T. Sharma, "Non-Coking Coal Quality and Composite PreReduced Pellets," Int. J. Miner. Process., 39 299-11 (1993).

14. R. Haque, H. S. Ray, and A. Mukherjee, "Packed Bed Reduction of Iron Ore Fines by Coal Fines: Effect of Operating Variables," Ironmaking Steelmaking, 19 [1] 315(1992).

15. D. H. S. John, S. P. Matthew, and P. C. Hayes, "The Breakdown of Dense Iron Layers on Wustite in $\mathrm{CO} / \mathrm{CO}_{2}$ and $\mathrm{H}_{2} /$ $\mathrm{H}_{2} \mathrm{O}$ Systems," Metall. Trans. B, 15 [4] $701-8$ (1984).

16. M. Rahman, R. Haque, and M. M. Haque,"Kinetics of Reduction of Millscale by Coal: Effect of Process Variables," Ironmaking Steelmaking, 22 [2] 166-70(1995).

17. D. H. S. John, S. P. Matthew, and P. C. Hayes, "Microstructural Changes during the Reduction of Wustite," Symp. Ser. - Australas. Inst. Min. Metall., 36 287-94 (1984).

18. G. S. Liu and V. Strezov, "Thermal Investigations of Direct Iron Ore Reduction with Coal," Thermochim. Acta, 410 $133-40$ (2004). 